\title{
O PAPEL DO DESIGN NA CONSTRUÇÃO DO PLACE BRANDING
}

Elisangela Batista da Silva

Doutoranda em Arquitetura (UFMG)

Mestre em Design (UEMG)

lili.batistabh@gmail.com

Resumo: O trabalho em questão propõe discorrer sobre os conceitos de marcas e de branding aplicados a países, cidades e lugares e correlacionar o papel do design na construção da imagem da marca de um país. O design é uma disciplina que pode proporcionar benefícios para todos. Dentro do contexto de uma cidade o design tem um alcance amplo. As competências de design podem transformar os centros urbanos a favor dos seus atores sociais, explicitando os seus anseios e necessidades, propondo experiências que provoquem emoções e traduzem culturas e identidades, seja nos campos da estratégia, da inovação, da estética, da forma e também na expressão cotidiana.

Palavras-chave: marcas, branding, cidades, design

\begin{abstract}
This work proposes discourse the concept of brands applied to countries, cities and places and correlate the role of design in brand establishment of a country. The design is a discipline that can provide benefits for all. Within the context of a city design has a broad reach. The skills of design can transform the urban centers in favor of its social actors, explaining their desires and needs, proposing experiments that cause emotions and translate cultures and identities, whether in the fields of strategy, innovation, aesthetics, form and also in everyday speech.
\end{abstract}

Keywords: brand, branding, cities, design 


\section{INTRODUÇÃO}

A globalização tem sido o principal argumento para o desenvolvimento do place branding. A construção de uma reputação positiva tem sido o objetivo de muitos países para se destacarem no mercado global. A proposta é diferenciar-se. Mas, para atingir tal proposito, é importante destacar que a construção de uma marca é permeada de inúmeros esforços para que a sua imagem seja constituída de elementos que crie uma relação efetiva entre a ela e os indivíduos.

O termo branding aplicado à países, cidades e lugares, tem sido motivo de muita discussão. Segundo Anholt (2007) quando se trata do assunto marca no contexto de países, cidades ou lugares, as pessoas tendem a pensar nas técnicas de persuasão usadas para promover a "venda" do país. E maioria não gosta disso. O autor ainda narra que um jornalista comparou a marca de lugares com a marca de gado: a aplicação de um logotipo atraente, um slogan atrativo e comercialização do lugar como se fosse apenas um produto no supermercado global.

Anholt (2007) lembra que é importante compreender o diferença entre marca e branding para assim, entender a proposta do place branding.

Portanto, esse artigo propõe uma revisão de literatura sobre assuntos relacionados à marca, branding e ao papel do design na construção da imagem da marca aplicada a lugares, cidades ou países, chamado place branding.

\section{MARCA E O BRANDING}

\subsection{Conceitos sobre marca}

A palavra marca, também conhecida como Brand na versão inglesa, está presente já há alguns séculos na vida das pessoas. As marcas fazem parte do cotidiano, das ruas, da vida dos indivíduos. E é essa onipresença que alimenta os conceitos sobre o que é uma marca. Costa (2011) corrobora essa premissa "é verdade que todo o mundo sabe o que é uma marca, porque vivemos rodeados de marcas e assediados por elas, mas a resposta à pergunta "o que é uma marca" varia conforme a quem perguntemos". (COSTA, 2011, p.17).

Anholt (2007), afirma que a maioria das pessoas pensa na marca como sinônimo de publicidade, promoção, designer gráfico ou relações públicas. Calder (2006) apresenta também essa questão “(...) se você perguntar o que é marca, a resposta é frequentemente longa (às vezes, tem a extensão de um livro!) e, geralmente, varia fortemente entre empresas consultores e diferentes autores." (CALDER, 2006, p. 28).

Costa (2011) relembra que o termo "marca" refere-se a condição essencial do ato de marcar, "uma marca é o sinal que deixa o ato de marcar, a marcação de uma matriz ou um traço sobre uma superfície."(COSTA, 2011, p. 20). Esse sinal impresso sobre alguma superfície, de forma intencional, comunica um significado para que os indivíduos entrem em ressonância com esse elemento, vinculando-o a uma identidade. E é esse conceito que remete aos primórdios da marca, quando era usada para identificar o gado.

A definição apresentada pela American Marketing Association (AMA) aproximase do conceito nascente. "Marca é um nome, termo, símbolo, desenho ou uma combinação desses elementos que deve identificar os bens ou serviços de um fornecedor ou grupo de fornecedores e diferenciá-los dos da concorrência." (KELLER, 2006, p.2). 
Para alguns autores, a marca apresenta também um aspecto mais intangível. 0 designer francês Joël Desgrippes citado por Gobé (2002) apresenta a seguinte ideia sobre o assunto:

Criar marcas não diz somente à onipresença, à visibilidade e às funções, mas também à ligação emocional com as pessoas na vida diária. É tão somente quando um produto ou um serviço provoca um diálogo emocional com o consumidor que realmente pode qualificar-se como Marca. (GOBÉ, 2002, p. 17)

Neumeier (2008) acompanha o raciocínio quando ele afirma que "a marca é um sentimento visceral de uma pessoal em relação a um produto, serviço ou empresa. Ela não é o que você diz o que ela é. Ela é o que os outros dizem que ela é." (NEUMEIER, 2008, p. 149).

Portanto, pode-se concluir que a marca abrange esses diversos conceitos, pois ela reúne os elementos tangíveis como o nome, logotipo e embalagem, importantes para identificar o produto ou serviço. E é também os aspectos intangíveis, sua reputação perante os indivíduos.

\subsection{A Marca - Identidade e Imagem}

A marca moderna abrange dois aspectos: a imagem física (logotipo, símbolos, embalagem, etc.) que é a representação física da imagem mental. Para alguns autores (Wheeler 2012, Costa, 2011, Anholt 2007) a imagem física, perceptiva da marca é chamada de "identidade da marca", e a imagem mental, simbólica é considerada "imagem da marca".

De acordo com Heilbrunn (2004) a identidade da marca, possui o atributo de garantir o reconhecimento imediato da empresa, produto ou serviço. Anholt (2007) lembra que esse aspecto é o cerne da concepção do produto, claramente e visualmente expressado. É o que o consumidor vê: a logo, o slogan, embalagem, o design do próprio produto. É também o aspecto que torna tangíveis as aspirações da marca.

a identidade da marca é tangível e faz um apelo para os sentidos. Você pode vê-la, tocá-la, agarrá-la, ouvi-la, observá-la se mover. A identidade da marca alimenta o reconhecimento, amplia a diferenciação torna grandes ideias e significados mais acessíveis. A identidade da marca reúne elementos díspares e os unifica em sistemas integrados. (WHEELER, 2012, p.14).

Segundo Aaker (1998) "o papel do símbolo, (...) é de ser um indicador (...) cujo resultado é um dispositivo mnemônico útil para o público-alvo." (Aaker, 1998 p. 212). O autor também lembra que o símbolo em uma marca, pode ser o condensador de valores relativos ao conhecimento, às associações e resultará na qualidade percebida e na lealdade.

Já a imagem da marca abrange, em seu contexto, aspectos da ordem do intangível reunindo em si propostas, conceitos, discursos, desejos, entre outros. Nesse processo existe o que a organização deseja que marca expresse. E existe o consumidor que sintoniza com a marca criando para si uma imagem mental sobre a marca.

À medida que concorrência cria uma infinidade de opções, as empresas passam a buscar formas de estabelecer uma ligação emocional com os clientes, tornar-se insubstituíveis e desenvolver relações duradoras. Uma marca forte se destaca em um mercado. As pessoas se apaixonam pelas 
marcas, confiam nelas e acreditam em sua superioridade. (Wheeler, 2012, p. 12).

Assim sendo, a imagem da marca abrange aspectos que vão além do incentivo ao consumo, elas criam um processo de identificação íntima com os indivíduos, o que abre espaço para a utilização da marca em outras esferas não comerciais, como por exemplo em ONGs, movimentos sociais, partidos políticos, entre outros. Calkins (2006) afirma que "Organizações que não visam lucros são marcas, grupos religiosos são marcas e qualquer pessoa é uma marca". (CALKINS, 2006, p. 2).

\title{
2.3 Branding - A gestão de marca
}

A complexidade da marca precisa ser organizada e gerenciada e esse processo de gestão de marcas é conhecido como branding:

\begin{abstract}
Branding é o conjunto de ações ligadas à administração das marcas. São ações que, tomadas com conhecimento e competência, levam as marcas além da sua natureza econômica, passando a fazer parte da cultura, e influenciar a vida das pessoas. Ações com a capacidade de simplificar e enriquecer nossas vidas num mundo cada vez mais confuso e complexo. (MARTINS, 2006, p. 8)
\end{abstract}

Costa (2011) e Aaker (1998) complementam a ideia de Martins (2006), ao lembrarem que a gestão de marca é um aspecto importante na gestão de ativos intangíveis, o seu simbolismo, o significado, discurso emocional, as mensagens, a identidade, a personalidade, a cultura, a reputação, o lado social são valores que estão associados a imagem da marca. A marca é um reflexo da percepção dos indivíduos.

De acordo com Wheeler (2012) por trás de toda marca de sucesso, existe uma estratégia que impulsiona o planejamento, o marketing e as vendas. Aaker (1998) lembra que esse posicionamento pode ser utilizado como uma maneira que a empresa deseja ser percebida. Ou seja, a comunicação da empresa determina, através da sua gestão, como ela deseja ser vista.

Porém, Neumeier (2008) afirma que "marca não é o que você diz que ela é. É o que os outros dizem que ela é. A marca é uma espécie de ideal platônico. Um conceito compartilhado pela sociedade para identificar uma classe específica de coisas." (NEUMEIER, 2008, p.3)

E Gobé (2002) nos seus estudos apresenta o conceito de branding emocional, cuja a base está no caráter humano, nas experiências, no desejo de ir além da satisfação material. Nesse conceito o design é o ponto fundamental para a gestão de marca.

Portanto, existem nesse processo de branding diferentes formas de gerenciar uma marca, que pode ser sob os aspectos mercadológicos em seu sentido mais direto, propondo um posicionamento do produto na mente do consumidor ou uma gestão que possui uma visão mais holística, que propõe a gerência da marca no âmbito das aspirações, dos ideais e da experiência, em que o consumo torna-se uma consequência do relacionamento marca e indivíduo.

\section{PLACE BRANDING}

Place Branding é o termo cunhado por Simon Anholt, um dos principais consultores e teóricos sobre o tema. Segundo o autor, trata-se do deslocamento de 
um conceito, até então pertencente a produtos e serviços, e agora aplicado a nações, cidades e lugares.

Anholt começou a escrever sobre o assunto em 1996 e a sua ideia inicial era que a reputação de países, que o autor estende para cidades e regiões, possui uma similaridade com a imagem da marca de produtos e organizações. E essa marca pode ser importante para a gestão de lugares.

Hoje, o mundo é um mercado. O rápido avanço da globalização significa que cada país, cada cidade e cada região tem de competir com todos os outros pela sua parcela de consumidores do mundo, turistas, investidores, estudantes, empresários, eventos esportivos internacionais e culturais, e pela atenção e respeito dos meios de comunicação internacionais, de outros governos, e as pessoas de outros países. ${ }^{1}$ (ANHOLT, 2007, P. 1)

De acordo com o autor, os países precisam desenvolver uma reputação favorável perante os outros países, para tornarem-se competitivos na comunidade global. Nesse aspecto, os países e cidades utilizam os seus nomes próprios como marcas.

Conforme articulado anteriormente, uma marca possui o aspecto tangível e a imagem mental. A tangibilidade, no caso de uma "marca-país", é o próprio lugar, o espaço físico, os aspectos sociais, políticos e econômicos. E não precisa ter necessariamente um logotipo, de acordo com o autor, pois essas técnicas não possuem muita relevância para países.

A imagem da marca é mencionada como atributo fundamental para o branding aplicado a lugares, pois os valores intangíveis creditados à marca pelo público externo, no caso de produtos e serviços é equivalente à reputação conquistada em relação à países, cidades e regiões. Aaker (1998) afirma que "a reputação de qualidade percebida é a base da vantagem competitiva sustentável para muitos negócios."(Aaker, 1998, p. 236). E são esses ativos conjugados que tornam a "marcapaís" expressiva.

Porém, Kotler et al (2006) já afirma que para implementar uma imagem eficaz de um lugar pode-se recorrer a três ferramentas: 1) Slogans, temas e posicionamentos, 2) Símbolos visuais e 3) Eventos e realizações. Mas o autor adverte que essas ferramentas de promoção devem respaldar-se na realidade, pois elas não solucionam problemas de base. Portanto, um anúncio com belas imagens e slogans envolventes que não condizem com a realidade são ferramentas para gerar uma imagem negativa do local em questão.

De acordo com Anholt (2010), usar as ferramentas de marketing só faz sentido quando aborda-se as ofertas de turismo, ou de produtos de exportação e serviços. Esses setores, quando bem comercializados proporcionam benefícios para a imagem da nação. Por exemplo a marca I LOVE NY, que foi desenvolvida em 1977 pelo designer gráfico Milton Glaser, em um momento crítico para New York, pois a cidade passava por sérios problemas sociais e econômicos foi desenvolvida com a intenção de

\footnotetext{
1 Tradução nossa - "Today, the world is one market. The rapid advance of globalization means that every country, every city and every region must compete with every other for its share of he world's consumers, tourists, investors, students, entrepreneurs, international sporting and cultural events, and for the attention and respect of the international media, of other governments, and the people of other countries." (Anholt, 2007, p. 1)
} 
valorizar a cidade e alavancar o turismo. Hoje, é considerada um referência de marca de cidade. A sua proposta foi replicada em outras cidades. Amsterdam, por exemplo fez um trabalho de valorização da própria imagem usando a marca I amsterdam em pontos estratégicos da cidade incentivando a fotografia desses lugares. O material captado foi publicado em um livro sobre a cidade.

Entretanto, quando o assunto é promover a imagem do lugar, sua política, cultura, educação, o seu povo, o uso do marketing pode gerar dúvidas. É importante considerar que a imagem de um lugar é muito mais vulnerável que a imagem de um produto ou serviço. Essa vulnerabilidade está relacionada com uma série de valores ideológicos, educacionais, culturais, econômicos e sociais que estão diretamente intricadas com as formas de governança e com os seus cidadãos. Aaker (1998) lembra que uma marca pode ter associações positivas ou negativas, o que no caso da imagem de um país, essas associações oscilam de acordo com as politicas públicas e seus cidadãos.

Anholt (2010) afirma que um país para adquirir uma imagem positiva deve-se concentrar em bons produtos, serviços, cultura, turismo, investimentos, tecnologia, educação, negócios, pessoas, políticas, iniciativas e eventos. O autor defende que os governos não devem tomar atitudes visando a gestão de imagem ou somente a mudança dessa imagem. Essas ações não devem ser vazias mas com propósitos relevantes.

Além dos atributos da imagem da marca Anholt (2010) apresenta outros pontos importantes para o place branding:

- Os lugares devem possuir uma relação clara, coordenada e comunicativa com o mundo exterior, pautada em um engajamento produtivo entre governo, empresas e sociedade civil. Esse processo deve ter harmonia dos objetivos, projetos, comunicação e comportamento a longo prazo.

- A noção de brand equity - A reputação é considerada um ativo muito valioso que necessita ser gerenciado, mensurado e alimentado ao longo do tempo.

- Outro ponto fundamental é a ideia de brand purpose - A importância dos grupos de pessoas em torno de uma estratégia comum pode criar uma dinâmica importante para o progresso. O autor ressalta que a "a gestão de marca é antes de tudo um projeto interno." (Anholt, 2010, p. 12)

- A inovação sustentável e coerente em todos os setores da atividade nacional que possam influenciar a opinião pública, e por consequência a mídia.

Esses aspectos, segundo o autor, devem ser entendidos e aplicados de forma responsável pelos decisores políticos, pois juntos, eles representam uma nova abordagem para a maneira em que lugares precisam ser gerenciados na era dos mercados globais.

\section{PLACE BRANDING E O DESIGN}

Segundo Moraes (2008), "uma disciplina como o design, pelo seu caráter holístico, transversal e dinâmico, posiciona-se como alternativa na aproximação de uma correta decodificação da realidade contemporânea." (MORAES, 2008, p.15). E são essas competências de design que podem transformar os centros urbanos a favor dos

\footnotetext{
2 Tradução nossa - "And that brand managenment is first and foremost an internal projet" (Anholt, 2010, p.12)
} 
seus atores sociais, explicitando os seus anseios e necessidades, propondo experiências que provoquem emoções e traduzem culturas e identidades.

As cidades são constituídas de artefatos e possuem um vasto campo de design. Cardoso (2012) considera como artefatos todos os objetos produzidos pela atuação humana e os divide em duas modalidades: os móveis e os imóveis. O autor questiona a existência de artefatos "imóveis", pois até mesmo esses objetos são passíveis de mudanças, seja de ordem tangível ou intangível.

Para o autor, existem seis fatores condicionados ao significado do artefato que possuem a capacidade de alterar essa imobilidade. Três estão ligados à materialidade do objeto: o uso, o entorno e a duração. E os outros três dizem respeito à percepção que os indivíduos fazem dele: o ponto de vista, o discurso e a experiência. Nesse sentido podemos considerar os espaços urbanos como artefatos que estão sujeitos à ação dos atores sociais, impregnados de significados que narram, através das visualidades, as histórias de uma cidade. Essas histórias normalmente evocam memórias e emoções.

Os Projetos de design urbano sugerem uma mudança na concepção e experiência dos seus espaços, e entram no campo do urbanismo e do lazer. Também nos aspectos da geografia, já que implicam mudanças nos status econômicos e culturais das cidades em um contexto global. (JULIER, 2008, p. $159)^{3}$

Os projetos de design devem considerar todos os aspectos de vivência e interação dos atores sociais com os espaços urbanos e a maneira como eles o utilizam, seja nos movimentos diários ou nos momentos de entretenimento. Os seus aspectos sociais, econômicos e culturais são preponderantes nos momentos de análise do espaço a ser projetado ou reestruturado pelo design.

As cidades podem ser revitalizadas pelo design. Segundo Lynch (2011) em uma cidade na qual já existem projetos urbanos, o design tem o papel de fazer uma reestruturação do ambiente, descobrir e preservar as imagens fortes, propor soluções para as dificuldades e ressaltar as identidades latentes.

Jullier (2008) cita o caso de Barcelona, que é um exemplo de cidade que teve a sua revitalização pautada pelo design. Muitas pessoas ignoram essa faceta que se iniciou nos anos 1980 e 1990 e foi motivada por sediar os Jogos Olímpicos de 1992. A infraestrutura da cidade estava descuidada, descaso resultante de quatro décadas de ditadura militar. $O$ processo de transição para a democracia despertou um reposicionamento ideológico, cultural e estético da região. $O$ design foi utilizado para posicionar e diferenciar a cidade. A sua imagem foi revitalizada, o sentimento de pertencimento foi reforçado com a criação da marca país, "Barcelona més que mai." (Barcelona mais que nunca) (JULIER, 2008, p.170). O seu novo design passou a fazer parte do cotidiano e incentivar um orgulho cívico pela cidade, apresentando uma nova Barcelona para o seus cidadãos e para o restante do mundo.

Lynch (2011) refere-se também a casos em que a proposta é de criação, de renovação do espaço urbano. O designer deve considerar todos os elementos que

\footnotetext{
${ }^{3}$ Tradução da autora. Texto original: Los proyectos de diseño urbano sugieren un cambio en la concepción y la experiência de lós espacios de la ciudade, y entran um el campo del urbanismo y um el ócio. También um el de la geografia, ya que implicam câmbios en el estatus econômico y cultural de las ciudades en un contexto global. (JULIER, 2008, p. 159)
} 
envolvem o lugar para desenvolver um projeto que acrescente e ou valorize as qualidades do local.

Os mobiliários urbanos são geralmente artefatos integrados aos espaços públicos e têm por objetivo oferecer serviços à população: seja na área do lazer, da limpeza, do descanso, entre outras. Estão diretamente ligados ao desenvolvimento econômico, social e cultural da cidade. O dicionário de urbanismo conceitua mobiliário urbano como:

\begin{abstract}
Conjunto de elementos materiais localizados em logradouros públicos ou em locais visíveis desses logradouros e que complementam as funções urbanas de habitar, trabalhar, recrear e circular: cabinas telefônicas, anúncios, idealizações horizontais, verticais e aéreas; postes, torres, hidrantes, abrigos e pontos de parada de ônibus, bebedouros, sanitários públicos, monumentos, chafarizes, fontes luminosas, etc. (FERRARA, 2004, p.240)
\end{abstract}

O Design desses artefatos, além de atender aos aspectos da funcionalidade, da acessibilidade, do conforto e da segurança dos seus usuários, deve propor uma integração com elementos culturais e sociais para uma maior interação entre os usuários. Muitos desses espaços tornam-se cenários de apresentações culturais, de encontros, de trocas de experiências.

Os bancos, postes de iluminação e balaústres fazem mais do que servir como
apoio ou assento para pedestres cansados: contribuem para redefinir a
identidade urbana através de suas formas. São detalhes arquitetônico, mas
que, também fazem parte de um tratamento gráfico da paisagem urbana. Sua
missão é de comunicar. (JULIER, 2004, p.159)

Segundo Montenegro, (2005) os atributos materiais (cor, forma, textura) e projetuais dos mobiliários dialogam com os seus usuários quando expressam a identidade, aspectos da cultura local, comportamentos e anseios. Devem também comunicar-se com a arquitetura e com a paisagem urbana.

As intervenções urbanas são manifestações localizadas que transformam o cotidiano. São consideradas arte de rua por alguns. Elas são, na maioria dos casos, de caráter experimental e são normalmente realizadas em espaços públicos, transformando-os em espaços comunicantes. São geralmente efêmeras, durando exatamente o tempo em que acontece. Em alguns casos os registros perduram por um tempo maior. Algumas intervenções são peças de teatro, manifestações culturais itinerantes ou mesmo publicitárias. No caso das expressões gráficas, desenhos, pinturas e grafites acontecem em espaços com aspectos abandonados ou degradados como muros, viadutos, pontes, paredes entre outros, ou áreas reservadas para esse intuito. Essas intervenções alteram a paisagem e o cotidiano do espaço urbano, com o forte apelo visual e temas que provocam emoções diversas nos transeuntes.

Bonsiepe (2011) cita os esforços das chamadas novas cidades de Design que exibem as creative industries para comprovar seu caráter excepcional. As novas cidades de Design são assim chamadas por possuírem uma identidade diferenciada

\footnotetext{
${ }^{4}$ Tradução da autora .Texto original: Los bancos, farolas y barandillas hacían algo más que servir como asidero o asiento para los transeuntes cansados: contríbuian a redefinir la identidad urbana a través de sus formas. Eran detalles arquitectónicos, pero también parte de un tratamiento gráfico del paisaje urbano. Su misión era comunicar.(JULIER, 2004, p.159).
} 
que se manifesta nas creatives industries, que são setores da indústria voltados para o entretenimento, moda, pesquisas de tendências, além da indústria tradicional. $O$ autor resume explicando que no geral trata-se branding de cidades para um determinado grupo social que possui condições de usufruir um determinado estilo de vida.

\section{CONCLUSÃO}

Percebe-se assim que o design em sua interdisciplinaridade possui ferramentas que podem proporcionar agregar valores à imagem da marca aplicada a lugares. A tangibilidade de suas ações resultam em valores intangíveis do bem-estar de viver, visitar e experienciar um lugar. Segundo Gobé (2010) “Design é mais do que o veículo que pelo qual as marcas se expressam e se conectam com seus clientes. (...) o design é um reflexo do ecossistema humano." (Gobé, 2010, p. 11).

E Uma marca deve ser o resultado de várias ações que decodifiquem e tangenciem os valores e imagem que uma cidade ou país precisam demonstrar. A criação de uma marca voltada para uma cidade deve ser a junção dos diversos elementos que a constitui, a sua identidade, os seus espaços urbanos e os significados a ela atribuídos.

E o design trabalhado de forma interdisciplinar, seja na arquitetura dos lugares, no mobiliário urbano, nas intervenções urbanas, na comunicação visual. Contribui de forma fundamental na formação da imagem da cidade, na sua marca.

\section{REFERÊNCIAS}

AAKER, David A. Marcas Brand Equity: Gerenciando o valor da marca. São Paulo: Negócio Editora, 1998.

ANHOLT, Simon. Competitive identity: The new brand management for nations, cities, and regions. New York: Palgrave Macmillan, 2007.

. Places: Identity, Image and Reputation. New York: Palgrave Macmillan, 2009.

BONSIEPE, Gui. Design, Cultura e Sociedade. Ed. Blucher: São Paulo. 2011

CALDER, J. Bobby. Design de Marcas. In: CALKINS, Tim; TYBOUT, Alice M.; (orgs). Branding. São Paulo: Atlas, 2006.

CALKINS, Tim. Introdução - desafio de branding. In: CALKINS, Tim; TYBOUT, Alice M.; (orgs). Branding. São Paulo: Atlas, 2006.

CARDOSO, Rafael. Design para um mundo complexo. São Paulo: Cosac Naify, 2012.

COSTA, Joan. A imagem da marca: Um fenômeno social. São Paulo: Rosari, 2011.

GOBÉ, Marc. A emoção das marcas: Conectando marcas às pessoas. Tradução de Fluvio Lubisco. Rio de Janeiro: Negócio, 2002.

GOBÉ, Marc. Brandjam: O design emocional na humanização das marcas. Tradução de Maria Clara de Biase. Rio de Janeiro: Rocco, 2010.

HEILBRUNN, Benoît. A logomarca. São Leopoldo: Ed. Unisinos, 2004. 
JULIER, Guy. La cultura del diseño. Tradução Marcos Muslera. Barcelona: GG Disenõ, 2008.

LYNCH, Kevin. A Imagem da Cidade. Tradução de Jefferson Luiz Camargo. 3. Ed. São Paulo. Martins Fontes. 2011.

KOTLER, Philip; GERTNER, David; REIN, Irving; HAIDER, Donald H. Marketing de Lugares. Prentice Hall Brasil, 2007.

MONTENEGRO, Glielson Nepomuceno. A produção do mobiliário urbano em espaços públicos. Dissertação de mestrado. 192fls. Universidade do Rio Grande do Norte: Rio Grande do Norte, 2005.

MARTINS, José S. A Natureza Emocional da Marca - Como escolher a imagem que fortelece a sua marca. São Paulo: Negócio Editora, 2004.

. Branding - Um manual para você criar, gerenciar e avaliar marcas. São Paulo: Global Brands, 2006.

MORAES. Dijon. Design e Complexidade. In: KRUCKEN, Lia; MORAES, Dijon; (orgs). COLEÇÃO: Cadernos de Estudos Avançados em Design, Transversalidade, Editora UEMG, 2008.

NEUMEIER, Marty. The brand Gap = 0 Abismo da marca: Como construir a ponte entre a estratégia o design. São Paulo: Bookman, 2008.

SEMPRINI, Andrea. A Marca Pós-Moderna: Poder e Fragilidade da Marca na Sociedade Contemporânea. São Paulo : Estação das Letras, 2010.

WHEELER, Alina. Design de identidade de marcas. Porto Alegre: Bookman, 2012.

RIBEIRO, Vinicius. Rafaella: um esquema para um novo paradigma de criptografia de chave pública.2005. 86 f. Tese (doutorado) - Universidade Federal do Rio Grande do Sul, Curso de Pós-Graduação em Ciências da Computação. 